\title{
The Search for Reliable Inputs in Modelling Hot Working Operations: A Model Describing the Flow Behavior of Metals at High Temperature Applied to CW602N Brass
}

\author{
M. El Mehtedi* AND S. Spigarelli
}

DIISM, Università Politecnica delle Marche, via Brecce Bianche 60131 Ancona, Italy

\begin{abstract}
Finite element modeling allows the optimization of metalworking processes and enhances the quality of the product, in terms of properties and microstructure, as attested by the success of recent finite element modeling codes in simulating the microstructural evolution during hot deformation. Hot working of metals involves several concurring phenomena; in particular, dynamic and static recrystallizations depend on the energy stored in the grains during and after deformation, i.e. on the strain accumulated in the material. As a result, the correct estimation of the accumulated strain plays a crucial role in modelling the final microstructure. A new constitutive model based on the combination of the Garofalo and Hensel-Spittel equations has been thus recently proposed to describe the plastic flow behavior of an aluminum alloys. The new equation was used in the present paper to model the equivalent stress vs. equivalent strain curved obtained by testing in torsion between 550 and $700{ }^{\circ} \mathrm{C}$ a $\mathrm{CW} 602 \mathrm{~N}$ $(\mathrm{Cu}-36 \% \mathrm{Zn}-2 \% \mathrm{~Pb}-\mathrm{As})$ brass. Interpolation of the experimental data using the constitutive model resulted in an excellent description of the flow curves, thus demonstrating that the combined use of the new equation and of torsion testing can be safely adopted in a computer code to simulate forging or extrusion.
\end{abstract}

DOI: 10.12693/APhysPolA.128.722

PACS: 83.10.Gr, 87.80.Ek

\section{Introduction}

A widely used approach [1-4] to model the plastic flow of metallic materials during high-temperature deformation is based on the Garofalo equation,

$[\sinh (\alpha \sigma)]^{n}=\dot{\varepsilon} A^{\prime} \exp \left(Q_{H W} / R T\right)$,

where $A^{\prime}$ and $\alpha$ are material parameters, $n$ is the stress exponent, and $Q_{H W}$ is the activation energy for hot working. Equation (1) is almost invariably used to describe the variation of the flow stress $(\sigma)$ with strain $(\varepsilon)$, temperature $(T)$ and strain rate $(\dot{\varepsilon})$, by supposing that $A^{\prime}, \alpha, n$ and $Q_{H W}$ are strain-dependent parameters. Polynomial equations are then used to describe the dependence of these parameters on strain, i.e.

$$
\begin{aligned}
& \alpha=B_{0}+B_{1} \varepsilon+B_{2} \varepsilon^{2}+B_{3} \varepsilon^{3}+B_{4} \varepsilon^{4}+B_{5} \varepsilon^{5}, \\
& n=C_{0}+C_{1} \varepsilon+C_{2} \varepsilon^{2}+C_{3} \varepsilon^{3}+C_{4} \varepsilon^{4}+C_{5} \varepsilon^{5}, \\
& \ln \left(A^{\prime}\right)=E_{0}+E_{1} \varepsilon+E_{2} \varepsilon^{2}+E_{3} \varepsilon^{3}+E_{4} \varepsilon^{4} \\
& \quad+E_{5} \varepsilon^{5}, \\
& Q_{H W}=F_{0}+F_{1} \varepsilon+F_{2} \varepsilon^{2}+F_{3} \varepsilon^{3}+F_{4} \varepsilon^{4} \\
& \quad+F_{5} \varepsilon^{5},
\end{aligned}
$$

where $B_{i}, C_{i}, E_{i}$ and $F_{i}$ with $i=0-5$ are material constants. A series of recent studies [5-7] demonstrated that, although this procedure in general provides excellent descriptions of the experimental data, extrapolation above the maximum experimental strain results in completely unreliable estimates of the flow stress. For large strains,

*corresponding author; e-mail: elmehtedi@univpm.it the calculated flow stress sometimes assumes even negative values. The combination of torsion testing and of a different computational approach was thus used to model the high-temperature response of different aluminum alloys [5-7]. The new constitutive model, which is based on an equation developed by Hensel and Spittel [8], in the form used in the present study, can be written as

$$
\begin{aligned}
& \sinh \left(\alpha^{\prime} \sigma / G\right)=A \exp \left(m_{1} T[\mathrm{~K}]\right) \varepsilon^{m_{2}}\left(\dot{\varepsilon}\left[\mathrm{s}^{-1}\right]\right)^{m_{3}} \\
& \quad \times \exp \left(m_{4} / \varepsilon\right)(1+\varepsilon)^{m_{5} T} \exp \left(m_{6} \varepsilon\right)
\end{aligned}
$$

where $A, m_{1}, m_{2}, m_{3}, m_{4}, m_{5}$ and $m_{6}$ are material parameters. The strain rate and the absolute temperature are normalized by the respective units $\left(\mathrm{s}^{-1}\right.$ and $\left.\mathrm{K}\right)$ to make $A$ a dimensionless constant.

\section{Experimental}

The alloy considered in the present study was the CW602N brass $(\mathrm{Cu}-36 \% \mathrm{Zn}-2 \% \mathrm{~Pb}-\mathrm{As}$, composition in wt\%). The material was tested in torsion; the hot torsion test is capable of producing strains of the order of 100 in ductile materials without the instabilities which cause barrelling and necking in compression and tension respectively. The torque $M$ and the number of revolutions $N$ were converted to the von Mises equivalent stress $\sigma$ and equivalent strain $\varepsilon$ at the surface

$$
\begin{aligned}
& \sigma=\frac{\sqrt{3} M}{2 \pi r^{3}}\left(3+n^{\prime}+m^{\prime}\right), \\
& \varepsilon=\frac{2 \pi N r}{\sqrt{3} L},
\end{aligned}
$$

where $r$ and $L$ are respectively the radius and the length of the gauge, $m^{\prime}=(\partial \log M / \partial \log \dot{N})$ is determined at constant strain, and $n^{\prime}=(\partial \log M / \partial \log N)$ at constant 
strain rate. For the sake of simplicity, both $n^{\prime}$ and $m^{\prime}$ were neglected after the pick value [9]. The surface equivalent strain rates were $10^{-2}, 10^{-1}, 1$ and $10 \mathrm{~s}^{-1}$. The specimens for torsion tests, $10 \mathrm{~mm}$ in diameter with a gauge length of $15 \mathrm{~mm}$, were strained, by a computercontrolled hot torsion machine at 550, 600, 650 and $700^{\circ} \mathrm{C}$. The samples were heated by a high frequency induction coil at $1{ }^{\circ} \mathrm{C} / \mathrm{s}$ from room temperature to the testing temperature and maintained at this temperature for $300 \mathrm{~s}$. Subsequently the samples were strained up to rupture.

\section{Results and discussion}

Figure 1 shows representative experimental curves obtained in the present study, and the model curves calculated by fitting the data by Eq. 3 (the Table). It can be easily observed that a good fitting of the data is obtained. For the sake of comparison, the experimental data were also fitted by a simplified version of the model based on Eqs. (1) and (2), i.e.

$$
\left[\sinh \left(\alpha^{\prime} \sigma / G\right)\right]^{n}=\dot{\varepsilon} A^{\prime} \exp \left(Q_{H W} / R T\right),
$$

with $n=4.5$ and $\alpha^{\prime}=250$, and

$$
\begin{aligned}
& \log \left(A^{\prime}\right)=E_{0}+E_{1} \varepsilon+E_{2} \varepsilon^{2}+E_{3} \varepsilon^{3}+E_{4} \varepsilon^{4}, \\
& Q_{H W}=F_{0}+F_{1} \varepsilon+F_{2} \varepsilon^{2}+F_{3} \varepsilon^{3}+F_{4} \varepsilon^{4}
\end{aligned}
$$

obtaining the $A^{\prime}$ and $Q_{H W}$ values plotted in Fig. 2. The figure also plots the values of the activation energy for self-diffusion in pure copper and for dislocation climb in $\mathrm{Cu}-30 \% \mathrm{Zn}$, as calculated by Raj [10]. The values of the activation energy for hot working are in general indicative of the micro-mechanisms controlling deformation. It is thus interesting to note that in the whole range of considered strain, the activation energy remains invariably higher than the activation energy for selfdiffusion, approaching its value $(202-211 \mathrm{~kJ} / \mathrm{mol}[10,11])$ only at $\varepsilon=0.75$. In addition, $Q_{H W}$ remains always substantially higher than the activation energy for climb, the recoverycontrolling mechanism. Substitution of Eqs. (6) in (5) leads to the model curves presented in Fig. 3. Again a good description is obtained in the early part of the curve, but a significant deviation is observed for large strains, as in the case presented in [5-7] for other materials. The situation does not substantially changes when 5 th order polynomial equations are used to describe the $A^{\prime}$ and $Q_{H W}$ dependence on strain. A confirmation that Eq. (3) gives a description more reliable that the models based on polynomial regression of the data is thus easily provided.

TABLE

Values of the parameters in the model Eq. (3), calculated by the fitting of the experimental data $\left(\alpha^{\prime}=250\right)$.

\begin{tabular}{c|c|c|c|c|c|c}
\hline \hline$A$ & $m_{1}$ & $m_{2}$ & $m_{3}$ & $m_{4}$ & $m_{5}$ & $m_{6}$ \\
\hline 6.72 & -0.00795 & 0.211 & 0.218 & -0.00623 & 0.0005 & -0.446
\end{tabular}

A problem of the model here presented, is that it does not contain an important parameter, the activation

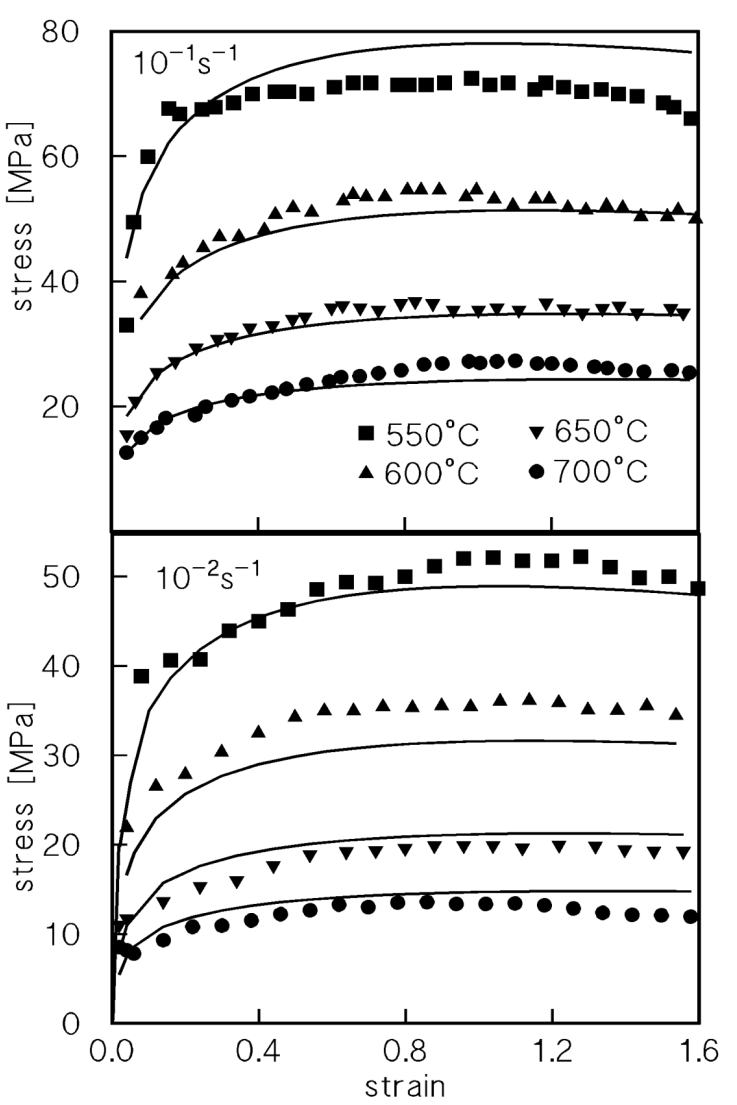

Fig. 1. Equivalent stress vs. equivalent strain at 0.01 and $0.1 \mathrm{~s}^{-1}$ for the CW602N brass; the Figure also shows the model curves obtained by Equation (3) (the values of the parameters are given in the Table).

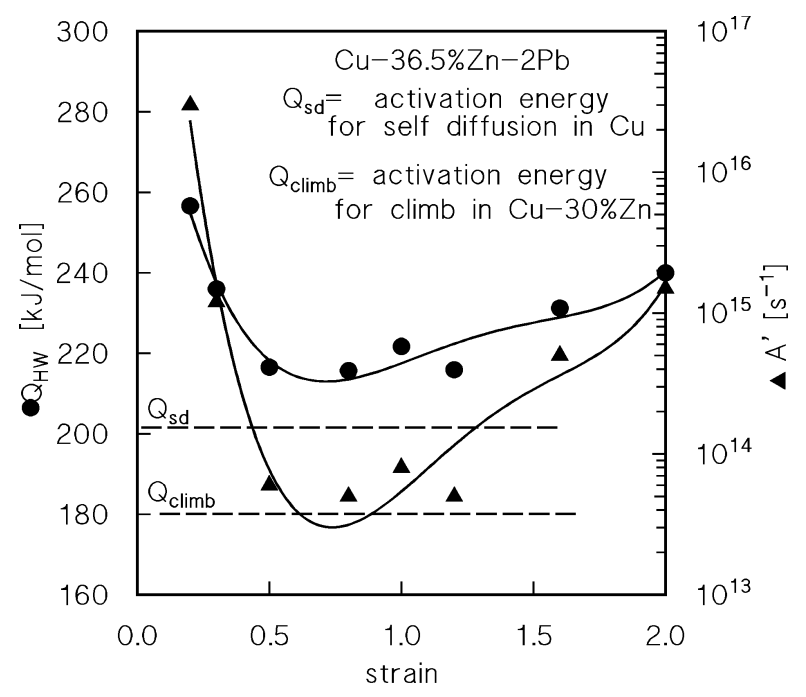

Fig. 2. Variation of $Q_{H W}$ and $A^{\prime}$ parameters in Equation (5) calculated from the experimental values of the flow stress as a function of strain rate, at different strains $\left(n=4.5\right.$ and $\left.\alpha^{\prime}=250\right)$. The curves represents the polynomial equations (6). The Figure also shows the values of the activation energy for self diffusion in pure $\mathrm{Cu}$ [11] and for climb in $70 \% \mathrm{Cu}-30 \% \mathrm{Zn}$ brass [10]. 


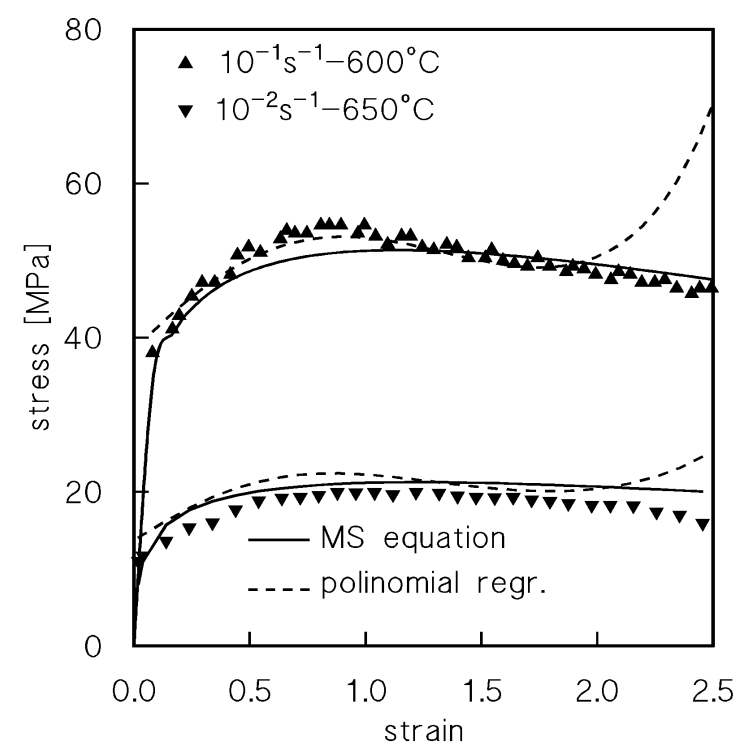

Fig. 3. Comparison between the model curves obtained by Equation (3) (solid lines) and those calculated by combining Equations (5) and (6) (broken lines).

energy for hot working $Q_{H W}$. Equation (3) does not explicitly contain the Arrhenius-term for the activation energy, but could be rewritten in the form

$$
\begin{aligned}
& {\left[\sinh \left(\alpha^{\prime} \sigma / G\right)\right]^{n}=\left[A \varepsilon^{m_{2}} \exp \left(m_{4} / \varepsilon\right) \exp \left(m_{6} \varepsilon\right)\right]^{n}} \\
& \quad \times \dot{\varepsilon}\left[\exp \left(m_{1} T / K\right)(1+\varepsilon)^{m_{5} T}\right]^{n}
\end{aligned}
$$

with $n=1 / m_{3}$ or

$$
\left[\sinh \left(\frac{\alpha^{\prime} \sigma}{G}\right)\right]^{n}=\dot{\varepsilon} A_{1}(\varepsilon) A_{2}(\varepsilon, T)
$$

being

$$
\begin{aligned}
& A_{1}(\varepsilon)=\left[A \varepsilon^{m_{2}} \exp \left(m_{4} / \varepsilon\right) \exp \left(m_{6} \varepsilon\right)\right]^{n}, \\
& A_{2}(\varepsilon, T)=\left[\exp \left(m_{1} T / K\right)(1+\varepsilon)^{m_{5} T}\right]^{n} .
\end{aligned}
$$

Comparison between (5) and (8)-(9b) gives

$$
\begin{gathered}
A_{3}(\varepsilon) \exp \left(Q_{H W}(\varepsilon) / R T\right)= \\
\quad\left[\exp \left(m_{1} T / K\right)(1+\varepsilon)^{m_{5} T}\right]^{n}
\end{gathered}
$$

with $A^{\prime}(\varepsilon)=A_{1}(\varepsilon) A_{3}(\varepsilon)$. Figure 4 plots the values of the activation energy for hot working and of the $A_{3}$ parameter as expressed in Eq. (10), their dependence on the strain being described by the relationships

$$
Q_{H W}=Q_{0}+k_{Q} \exp \left(-c_{Q} \varepsilon\right)
$$

and

$$
\log A_{3}=\log A_{0}+k_{A} \exp \left(c_{A} \varepsilon\right),
$$

where $Q_{0}, A_{0}, k_{Q}, k_{A}, c_{Q}$ and $c_{A}$ are material parameters. Figure 4 shows that for $0<\varepsilon<2, Q_{H W}$ decreases from 242 to $225 \mathrm{~kJ} / \mathrm{mol}$, in good agreement with the average value of $220 \mathrm{~kJ} / \mathrm{mol}$ obtained by calculating the strain rate dependence of peak flow stress [12]. On the other hand, the microstructural analysis of the deformed

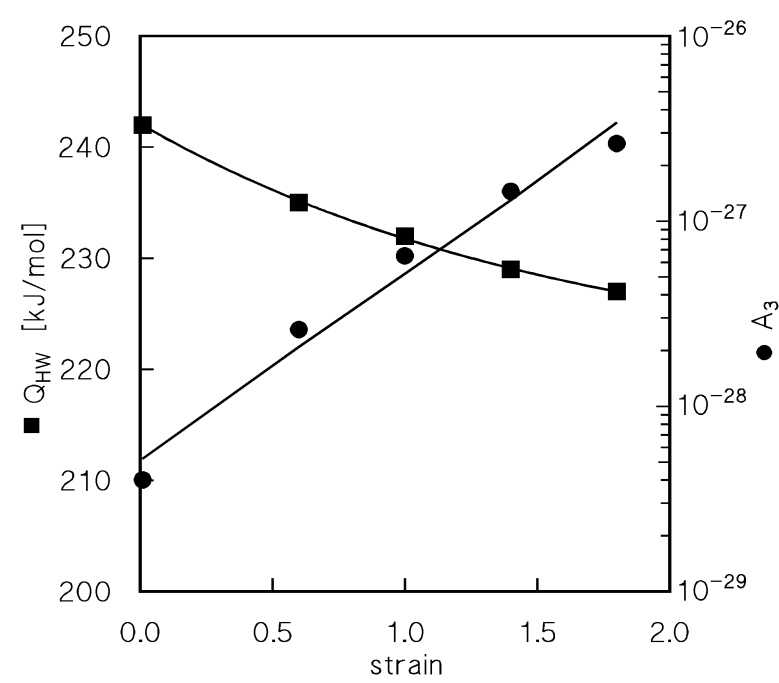

Fig. 4. Variation of $Q_{H W}$ and $A_{3}$, from equation (10), as a function of strain.

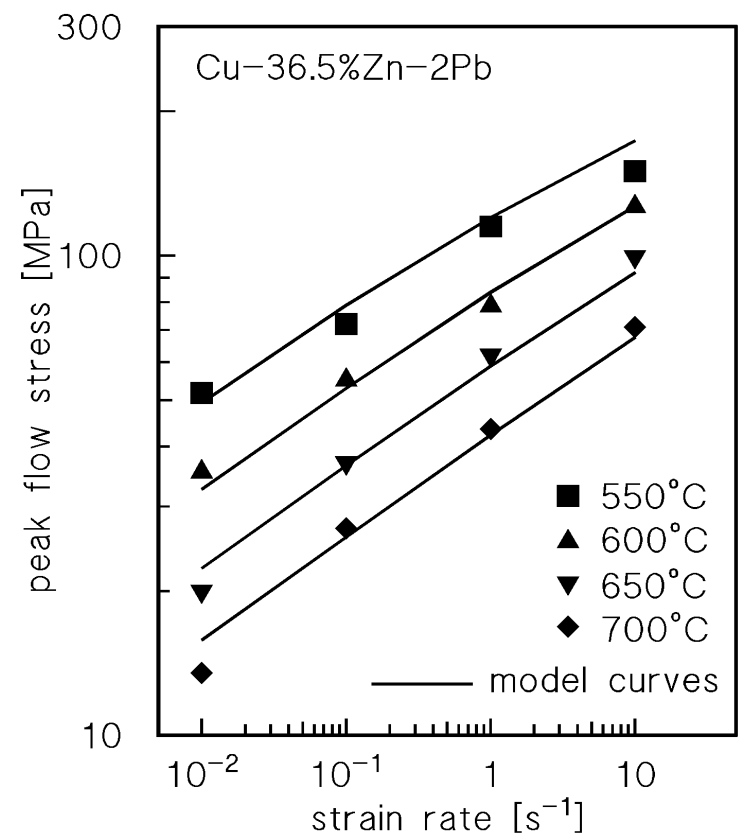

Fig. 5. Comparison between experimental and calculated values of the peak flow stress; the latter were obtained by identifying the maximum in the model curves given by Equation (3), with the parameters reported in the Table.

samples (illustrated in [12]) clearly indicated that the microstructure of this material is predominantly composed by the $\alpha$ solid solution of $\mathrm{Zn}$ in $\mathrm{Cu}$, with minor but not negligible (5-10\% in volume) presence of $\beta$ bcc-phase. Since the $\beta$-volume fraction increases with temperature, the calculation of $Q_{H W}$ is significantly affected by the progressive precipitation of this softer phase. Thus, $Q_{H W}$ cannot be easily related to a single micromechanism, but is rather the result of the combination of different overlapping phenomena, such as climb-controlled recovery, 
dynamic recrystallization and precipitation of the soft $\beta$ phase. On these bases, it appears more correct to define $Q_{H W}$ as an "apparent" activation energy for hot working, thus dropping the idea of easily identifying a single strain-controlling mechanisms by merely considering the magnitude of its value.

Figure 5 compares the experimental values of the peak flow stress with those obtained from the model curves. An analysis of the figure clearly indicates that the model gives also an adequate description of the peak stress, significant deviations being only observed in the cases of the extreme testing conditions $\left(550{ }^{\circ} \mathrm{C} ; 10 \mathrm{~s}^{-1}\right.$ and $\left.700{ }^{\circ} \mathrm{C} ; 0.01 \mathrm{~s}^{-1}\right)$.

\section{Conclusions}

A new constitutive model, based on the combination of the Hensel-Spittel and Garofalo equations was used to describe the hot working behavior of the CW602N brass. Interpolation of the experimental data by the constitutive model resulted in an excellent description of the flow curves. The combined use of the new equation and of torsion testing led to the development of a constitutive model which can be safely used in a computer code to simulate metal forming operations.

\section{References}

[1] J. Li, F. Li, J. Cai, R. Wang, Z. Yuan, F. Xue, Mater. Des. 42, 369 (2012).

[2] H.R. Rezaei Ashtiani, M.H. Parsa, H. Bisadi, Mater Sci. Eng. A545, 61 (2012).

[3] N. Haghdadi, A. Zarei-Hanzaki, H.R. Abedi, Mater. Sci. Eng. A535, 252 (2012).

[4] Y.C. Lin, Y.-C. Xia, X.-M. Chen, M.-S. Chen, Comput. Mater. Sci. 50, 227 (2010).

[5] M. El Mehtedi, F. Musharavati, S. Spigarelli, Mater. Des. 54, 869 (2014).

[6] M. El Mehtedi, S. El Mohtadi, S. Spigarelli, Key Eng. Mater. 585, 59 (2014).

[7] S. Spigarelli, M. El Mehtedi, J. Mater. Eng. Perf. 23, 658 (2014).

[8] A. Hensel, T. Spittel, Kraft und Arbeitsbedarf bildsamer Formgeburgsverfahren, VEB DeutscherVerlag fur Grundstofindustrie, Leipzig 1978.

[9] J. Castellanos, I. Rieiro, M. El Mehtedi, M. Carsí, O.A. Ruano, Int. J. Mater. Res. 101, 787 (2010).

[10] S.V. Raj, J. Mater. Sci. 26, 3533 (1991).

[11] D.B. Butrymowicz, J.R. Manning, M.E. Read, J. Phys. Chem. Ref. Data 2, 643 (1973).

[12] S. Spigarelli, M. El Mehtedi, M. Cabibbo, in: Proc. ISPMA 13 Conf., Prague, 2014 